\title{
Breast Cancer Disease and Arsenic: "Geological Behavior (GBR) as Key "6
}

${ }^{I}$ Nutrition and Food Sciences Research Center, Tehran Medical Sciences, Islamic Azad University, Tehran, Iran

${ }^{2}$ Department of Chemical Engineering, Shiraz Branch, Islamic Azad University, Shiraz, Iran

${ }^{3}$ Manager Director, ELIDAN america LLC, Fl, USA.

${ }^{4}$ CEO, ELIDAN genome SAS, 1 avenue du Lycée, 77130 Montereau Fault Yonne; France.

\section{"Correspondence author}

Dr. Luis CRUZ-RODRIGUEZ

Manager Director

ELIDAN dynamic LLC

FL,USA

ORCID : https://orcid.org/0000-0002-7539-2382

E-mail : ceo@elidan-genome.com, luis.cruzrguez@gmail.com

Submitted : 26 Aug 2020 ; Published : 14 Sept 2020

\begin{abstract}
Geology may appear remote from human health. However, rocks are the fundamental building blocks of the Earth's surface, full of important minerals and chemical elements. Rock weathering and alteration products not only form our soils to support our crops but provide essential elements to build biology. Some heavy metals are carcinogenic, and some only affect the body's ability to produce red and white cells. In fact, any heavy metal affects any part of the body due to our geological behavior (GBR). For example, a heavy metal may not cause any side effects by contact with the skin, even when swallowed, and may not cause serious harm, but inhaling the vapor of that heavy, toxic metal can cause severe damage to the lungs. Some heavy and quasi metals are more toxic, and some forms of heavy metal compounds are even more dangerous than other forms. Toxic and hazardous heavy metals like arsenic, lead, mercury, zinc, chromium and iron are found in a variety of personal care products, e.g., lipstick, whitening toothpaste, eyeliner and nail color. We use the Anodic Stripping voltammetry (ASV) method for arsenic detection, utilizing the PDV6000 + analyzer (Manufactured B3 Electronics, Perth Australia) configured with a solid gold electrode for total as analyses. Sample Preparation: Spot urine samples were collected from most of the participants from 1 January 2018 to 30 March 2020 after face to face interviews. Women with missing information on adjustment variable(s) were included in the analysis in a separate category for adjustment. Results: Our studies were focus in describing the mean Urinary Arsenic levels (u As) residents of in the central zones of Shiraz, Fasa, Abadeh, Jahrom and Marvdasht to compare the effect of diet such as consuming canned or frozen foods, Consume rice daily, smoking habits and lifestyle on the incidence of Breast. Conclusion: Cancer with arsenic compounds has been reported in many parts of the world. The disease affects all organs of the body, and every year many victims of cancer suffer from severe symptoms and even death. Arsenic compounds are present in the human body and environment in an inorganic and organic form. Inorganic arsenic includes arsenite and arsenic, can also be presented in the environment in the form of methyl (monthly arsenic acid and dimethyl arsenic acid). Arsenic, especially inorganic arsenic, is well absorbed through the gastrointestinal tract rivers ( $80 \%-90 \%)$ and will be scattered throughout the body. It is often metabolized by methylation and excreted mainly in the urine. Methylation of inorganic arsenic compounds is said to undergo a detoxification process.
\end{abstract}

Keywords: Breast Cancer, heavy metal, Arsenic, As, lifestyle, geological behavior (GBR)

\section{Highlights}

- Urinary Arsenic concentration in Breast Cancer patients over 40 years old was 5 times, and in patients, 20-40 years old group was 4 times more than control groups.

- Urinary Arsenic contents in Breast cancer patients in all ages category are much lower by eating Green peppers stuffed with Foods frequently $(\mathrm{p}<0.001)$.

- U As level was significantly higher in direct correlation between anthropometric factors (BMI levels; $\mathrm{p}<0.041$, dietary habits such as eating frozen and canned foods, Tuna, raw mushrooms, use of colorful cosmetics and
Tattoo and behavior of lifestyle was found in all patients of cases and control.

- Drinking Herbal Tea caused decreased u Arsenic concentration in both older and younger age subgroups.

- Consuming Indian rice, history of cancer in the family, smoking, Routine exposure to household chemicals significantly increase the risk of breast cancer. 
Introduction

One of the concerns that have attracted a lot of attention in recent years is the issue of human pollution and poisoning by exposure to heavy and quasi metals. Heavy metals are mostly toxic compounds that the body can hardly excrete in just a small amount, and the accumulation of large amounts of them can lead to dangerous side effects. Heavy and quasi metals enter the human body through various means such as food consumption, breathing polluted air and contact with contaminated water and soil. In general, the symptoms of a person exposed to heavy metals depend on the type of heavy metal, the type and amount of contact, the person's age, and the person's health status. When large amounts of heavy metals enter the body, they accumulate in the kidneys, liver, bone, and brain, disrupting that part of the body. Some heavy metals are carcinogenic, and some only affect the body's ability to produce red and white cells. In fact, any heavy metal affects any part of the body. For example, a heavy metal may not cause any side effects by contact with the skin, even when swallowed, and may not cause serious harm, but inhaling the vapor of that heavy, toxic metal can cause severe damage to the lungs according to GBR. Some heavy and quasi metals are more toxic, and some forms of heavy metal compounds are even more dangerous than other forms. Toxic and hazardous heavy metals like arsenic, lead, mercury, zinc, chromium and iron are found in a variety of personal care products, e.g., lipstick, whitening toothpaste, eyeliner and nail color. Some heavy metals are used in cosmetics as ingredients, while most of the others are contaminants [1,2]. Cadmium is a highly stable toxic metal that accumulates in the body over time and mimics the effects of the hormone estrogen on the body. This explains why cadmium is linked to hormone-dependent cancers. Evidence suggests that cadmium exposure is associated with problems such as kidney damage, calcium imbalance and an increased risk of pancreatic, breast and endometrial cancer [2]. Ziarati et al. studied-on the Cd level in Breast Cancer patients and investigated the long term using of menopausal hormone therapy for several months or longer in the total population of cases and control [2]. Quasi-metals such as arsenic have properties between metals and non-metals. Environmental and climatic conditions in each region contribute to the occurrence and spread of some diseases. These contaminants are exposed to the public in a variety of ways, including natural resources, groundwater, soil leaching, industrial processes, commercial products, and food supplements $[3,4]$. One of these pollutants is arsenic compounds, which are used in the manufacture of glassware, metal alloys, microelectronics, agricultural pesticides and wood preservatives. Arsenic, in Persian, is called the oxide of rat death and its sulfide is Zarnich. Arsenic is a well-known toxic metal that is found in three forms: yellow, black, and gray. Arsenic and its compounds are used as pesticides: herbicides, insecticides and various alloys. Humans are exposed to arsenic in the air, food and water. Drinking water may be caused by insecticides contain arsenic, mineral deposits or residual chemical contaminants containing arsenic. Arsenic Drinking water is the most important cause of arsenic poisoning worldwide [5]. Arsenic is released during the process of mineralization and the combustion of fossil fuels. Arsenic is also naturally distributed in the air following volcanic activity, microbiological and global warming, and the destruction of the surface layers of rocks. In many areas, the presence of larger amounts of arsenic raises serious concerns for human health $[1-3,6]$. Arsenic is a chemical element with the abbreviation As, an atomic number 33, and atomic weight 74.92. This element is present in many minerals, in combination with sulfur and other metals, as well as pure crystalline elements. Arsenic forms significant toxic metabolites if converted to its allotropic forms [7]. Inorganic arsenic is tasteless and odorless and through the gastrointestinal tract $\%(80-90 \%)$ and its smaller particles. It is often absorbed in the small intestine and subsequently in the colon and also the respiratory system, intravenous and skin. The mucosa is another center that is responsible for absorbing arsenic. Dissemination throughout the body, often by Methylation is performed [8]. In general, arsenic causes changes in structure, DNA damage to mitochondria, changes in methylation, DNA Oxidative stress, abnormal cell proliferation, carcinogenicity, and the likelihood of tumor enlargement. This can cause tumors of the skin, bladder, liver, prostate, breast, kidneys and other parts of the body $[9,10]$. Therefore, groundwater pollution has become a global health and environmental concern. Maximum acceptable concentration (MAC) of arsenic in drinking water is $0.01 \mathrm{mg} / 1(10 \mu \mathrm{g} / \mathrm{l}=10 \mathrm{ppb})$ in Canada. Maximum acceptable concentration (MAC) of arsenic in drinking water is $0.01 \mathrm{mg} / 1$ $(10 \mu \mathrm{g} / \mathrm{l}=10 \mathrm{ppb})$ in Canada. Acceptable limits of oral ingestion of arsenic are $0.1 \mathrm{ppm}$ in foods [11], and 3ppm in nutritional supplements (USP). FDA limit for arsenic in certain colorants is $<3 \mathrm{ppm}$. [12-14]. It is estimated that about 150 million people in the world are affected by this substance, and the identified infected areas are still increasing. Prolonged use of this toxic substance in water or food can lead to skin disorders, peripheral vascular disease, hypertension, a variety of cancers, including breast cancer in women, diabetes and neuropathy $[15,16]$. Lack of smell, taste and color makes it impossible to identify and avoid arsenic. According to WHO guidelines on water consumption, more than 150 million people across the globe are at risk for chronic arsenic contamination, of which more than 45 million live in Asia, most of them in developing countries [17]. Drinking water with an arsenic concentration of more than 50 micrograms per liter for at least a year can lead to several complications, the most common of which are called arsenicosis [18-20].

Today, there is a strong link between diet and breast cancer has become quite apparent. It is estimated that more than a third of cancers are related to our eating habits. People's eating habits can also affect how the body fights disease. In general, factors such as high-fat diets, high-calorie diets, obesity, alcohol and smoking increase the risk of breast cancer, while eating fresh vegetables and fruits, certain salts and vitamins, flavonoid and herbal compounds and exercising can reduce the risk of developing the disease. According to the World Health Organization, proper nutrition programs can reduce breast cancer mortality remarkably [21,22]. 
In Asia, the presence of arsenic in the groundwater of Bangladesh, Cambodia, China, India, Japan, Myanmar, Nepal, Pakistan, Thailand, Vietnam and Iran has been reported [23]. In Iran, arsenic in nature is responsible for contaminating drinking water. Kurdistan, the western province of the country in Iran, has the most problems in this regard [24]. Cancer is one of the diseases that are affected by environmental factors and its incidence varies in different geographical areas.Numerous researchers have conducted research in this area, including López-Carrillo and col., in 2014, examined the potency of arsenic methylation and its association with breast cancer in women in northern Mexico [25]. Lin et at; in 2005 investigated the Synergistic effect of all-trans-retinoic acid and arsenic trioxide on tumor growth in breast and lung cancer [26]. Khanjani in 2017, systematically reviewed the epidemiological study of arsenic-associated breast cancer [27]. López-Carrillo in 2020 revisited Inorganic arsenic methylation capacity and breast cancer by immunohistochemical subtypes in northern Mexican women [28]. Cioloboc, D in 2020, and Palma-Lara in 2020 also examined the effects of arsenic on general health problems that lead to a variety of cancers $[29,30]$. Other researchers have also studied the effects of arsenic on other diseases. For example, a 1988 study by Guha Mazumder et al. Showed that chronic arsenic poisoning can lead to pigmentation disorders, hyperkeratosis, hypertension, diabetes, anemia, weakness and ischemic heart disease [15]. A 2004 study by Yoshida et al. Showed that lesions skin, vascular disease, hypertension, diabetes, and neurological complications are more common as a result of chronic arsenic use in water [31]. Mahram et al. in 2013 concluded that high levels of arsenic in drink water even 20-30 micrograms per liter related to an increased prevalence of diabetes mellitus and hypertension [31]. Rahmani et al. in 2001 showed that chronic consumption of water contaminated with arsenic increases the prevalence of hyperkeratosis, hypertension, diabetes and heart disease [20]. Mosaferi et al. .in 2008 found that the relationship between arsenic-containing water was higher than allowed increased prevalence of hyper and hypopigmented skin lesions and hyperkeratosis, hypertension and showed chromosomal abnormalities [24]. Therefore, the need for research on the epidemiology and the prevalence of various cancers, as the third leading cause of death in Iran, is significant. Gathering information about cancer epidemiology is the first step in controlling the disease. According to the previous study, Cadmium was an important key in Breast Cancer disease [2]. Now since the name of Iran is one of the areas with water contaminated with arsenic above the permitted level and cases, and because of the importance of breast cancer in women in Fars province and its relationship with arsenic consumption, the research team decided to conduct a comprehensive and complete research on the relationship between arsenic environmentally and daily exposure and nutrition in women in the Health Network (Fars Province) to have water contaminated with arsenic above the permissible level, to examine the effects of breast cancer among the residents and if identify patients with the necessary diagnostic measures. Nutritional habits and lifestyle are also fundamental issues. Therefore, in this study, the amount and manner of reports of breast cancer resulting from arsenic to the Fars Cancer Registration Center were examined and discussed in detail.

\section{Materials and Methods}

The Anodic Stripping voltammetry (ASV) method for arsenic is employed, utilizing the PDV6000 + analyzer (Manufactured B3 Electronics, Perth Australia) configured with a solid gold electrode for total as analyses. The instrument uses a platinum counter electrode and silver/silver chloride reference electrode. $1 \mathrm{M} \mathrm{KCl}$ is injected into the counters electrode cell, separated from the sample with a frit, soaked in distilled water overnight. The silver electrode is plated with $1 \mathrm{M} \mathrm{KCl}$ in an electric cell with power supply provided, for no longer than $5 \mathrm{~min}$., achieving an even brown or black coat of silver chloride after first cleaning the silver rod with fine white emery if degraded.

Chemtronics Protocol No AN027v2 is employed, the instrument connected to a PC running the VAS software supplied. After a voltammogram is achieved, The Standard Comparison (SC) technique is suitable for most samples that have low organic content, such as a clean river, lake, and seawater. With interferents, standard additions overcome some of the matrix effects. For excessively dirty samples, digestion of the matrix is carried out before. Analysis with VAS software and standard addition LDL of approximately $2 \mathrm{ppb}$, as is achieved with $5 \%$ coefficient of variation over 5 clean samples at $50 \mathrm{ppb}$ in solution. Arsenic (III) Standard (20 ppm) is employed.

The sample is run on linear sweep parameters as follows; Rest potential, $500 \mathrm{mV}$; condition time $30 \mathrm{~s}$; Mix potential, $500 \mathrm{mV}$; Deposit potential, $-900 \mathrm{mV}$; Hold potential, $-200 \mathrm{mV}$; Hold time $15 \mathrm{~s}$; measure start potential, $-5 \mathrm{mV}$; measure stop potential, $400 \mathrm{mV}$; Sweep rate, $500 \mathrm{mV} / \mathrm{s}$, Clean time $10 \mathrm{~s}$, range $100 \mathrm{uA}$. AV conditioning parameters are as follows; conditioning potential, $0 \mathrm{mV}$; alternate potential, $800 \mathrm{mV}$; alternating duty cycle, 50; cycle period $0.2 \mathrm{~s}$; sweep start potential $-200 \mathrm{mV}$, sweep stop potential $600 \mathrm{mV}$; step size $1 \mathrm{mV}$; step duration $2 \mathrm{~ms}$, sample time 1550us, samples per step 16.

Blanks were run in of $0.5 \mathrm{M} \mathrm{M} \mathrm{HCL}$ three times to ensure electrodes are clean after polishing. Samples are then run with single comparison, or if metric effects are experiences, noted by suppressed or double peaks, standard additions are employed in the Peaks are observed between $+50 \mathrm{mV}$ to $+300 \mathrm{mmV}$, dependent on matrix.

If necessary, electrode conditioning was employed utilizing $1 \mathrm{ppm}$ as standard in $0.1 \mathrm{M}$ electrolyte, run as a standard a few times to increase the sensitivity of the gold electrode.

Interferents may be experienced with high $\mathrm{Cu}$ due to peak overlap. This has had previously been established at 50ppb As, 20\% peak drop at ppb: $\mathrm{Cu} 50, \mathrm{~Pb} 100, \mathrm{Zn} 200, \mathrm{Ag} 250, \mathrm{Hg}, 500$, Fe2000. 20ml sample cups. Continuous analysis of solutions containing Selenium (Se) can gradually foul the electrode. In this case, Clean Potential of $+750 \mathrm{mV}$ minimizes a reduced as a response. 
Study Population

Current research is a population-based cross-sectional study initiated in the central zones of Shiraz, Fasa, Abadeh, Jahrom and Marvdasht (all patients have been coming to hospitals located in Shiraz, the capital of Fars Province) to compare the effect of diet, smoking habits and lifestyle on the incidence of Breast Cancers (stages I to III Breast Cancer usually includes surgery; as Stage III is divided into subcategories known as IIIA, IIIB, and IIIC.) in a total study population of 125 Breast Cancer patients in different subgroups of the over 40 years participated along with 39 women in the control group at the same time, and also in table 2 for 101 patients in the range of 20-40 years in comparison by 49 women in the control group in the same central zones in Fars province, with incident invasive Breast Cancer identified. This is a descriptive-analytic and a cross-sectional study performed from 1 January 2018 to 30 March 2020. The study population consisted of six hospitals affiliated to Shiraz University of Medical Sciences and all hospitals were teaching hospitals.

\section{Sample Preparation}

Spot urine samples were collected from most of the participants from 1 January 2018 to 30 March 2020 after face to face interviews. Women with missing information on adjustment variable(s) were included in the analysis in a separate category for adjustment. No single variable had data missing for more than $10 \%$ of participants. In sensitivity analyses, the reports were repeated including only women with complete information on all variables.

\section{Data collection}

Face-to-face interviews based on structured and food frequency questionnaires were utilized to obtain demographic lifestyle and dietary information by trained staff at the time of study enrolment. Food-Frequency Questionnaires (FFQ) are designed to assess dietary patterns by collecting information regarding the frequency with which specific food items are consumed over a specified reference period. It should be noted that the FFQ was designed based on the local community foods, especially for young and older adults living in Fars province.

General characteristics including age, weight, height, women body mass index (BMI), education levels, family history of Breast Cancers, history of other cancers in the family, Marital status, reproductive history (including use of menopausal hormone therapy for 3 months or longer (estrogen or estrogen plus progesterone; pills or patches), occupational status, second hand or active smoke ( $>30 \mathrm{~min} /$ day), physical activity, living and working address (urban or rural areas), dietary habits, occupational exposure to Arsenic, exposure to household chemicals, using plastics dishes or plastic water bottles, using a home water purifier, postmenopausal hormone use, using Arsenic containing cosmetics (eye shadow) and having "Tattoo" were asked from the volunteers and recorded in their structured questionnaires. The heights and weights of volunteers were measured at the time of study enrolment. parent study, who completed the interview, was $71 \%$ for case participants and $87 \%$ for control participants. Of those who completed the meeting and agreed to participate in the metal sub-study, a participation proportion of $80 \%$ was achieved for urine specimen returns for both case and control participants. The University of Shiraz, Educational hospital subjects Committee approved this study. Oral consent was obtained for the interview and written informed consent was obtained for the urine specimen collection.

\section{Data analysis method}

Multivariate logistic regression models were used to assess the effects of urinary Total Arsenic levels on Breast Cancer risk, controlling for age and for suspected or established risk factors (age, weight, height, BMI, education levels, family history of Breast Cancers, history of other cancers in the family, marital status, reproductive history, occupational status, second hand or active smoke( $>30 \mathrm{~min} /$ day $)$, physical activity, living and working address (urban or rural areas), dietary habits such as Drinking Herbal Tea; consuming fast foods, Canned, prepared foods; Mushrooms in raw or cooked states; Green peppers in weekly diet, Occupational or household exposure to As, postmenopausal hormone use, using As containing cosmetics and having "Tattoo."

\section{Moral considerations}

According to the codes approved by the National Ethics Committee in Medical Sciences Research, all information taken from patients, it remains confidential, and the results of the research will be published in general and in the form of details of the study group and the individual results will be presented without mentioning the name and personal information.

\section{Results}

This section analyzes the data based on the specific objectives of the research.

Table 1 and 2 describe the mean Urinary Arsenic levels (u As) residents of in the central zones of Shiraz, Fasa, Abadeh, Jahrom and Marvdasht (all patients have been coming to hospitals located in Shiraz, the capital of Fars Province) to compare the effect of diet such as consuming canned or frozen foods, Consume rice daily, smoking habits and lifestyle on the incidence of Breast Cancers (stages I to III Breast Cancer usually includes surgery; as Stage III is divided into subcategories known as IIIA, IIIB, and IIIC.) in a total study population of 125 Breast Cancer patients in different subgroups of the over 40 years participated along with 39 women in the control group at the same time, and also in table 2 for 101 patients in the range of 20-40 years in comparison by 49 women in the control group in the same central zones in Fars province, with incident invasive Breast Cancer identified. This is a descriptive-analytic and a cross-sectional study performed from 1 January 2018 to 30 March 2020. 


\begin{tabular}{|c|c|c|c|}
\hline Characteristics & $\begin{array}{l}\text { Women } \\
(\mathrm{n}=125)\end{array}$ & $\begin{array}{l}\text { Control } \\
\text { group } \\
(\mathrm{n}=39)\end{array}$ & p-Value \\
\hline $\begin{array}{l}\text { Age (mean } \pm \\
\text { SD) }\end{array}$ & $53.28+4.87$ & $\begin{array}{l}54.78+ \\
6.04 \\
\end{array}$ & 0.148 \\
\hline $\begin{array}{l}\text { As levels } \\
(\text { Mean } \pm \text { SE }\end{array}$ & $0.054+0.009$ & $\begin{array}{l}0.011+ \\
0.008\end{array}$ & $0.004 * *$ \\
\hline $\begin{array}{l}\text { Body Mass } \\
\text { Index (BMI) } \\
(\text { mean } \pm \text { SD) }\end{array}$ & $27.111+0.672$ & $\begin{array}{l}25.007+ \\
0.928\end{array}$ & $0.041 *$ \\
\hline Education(yes) & 22 & 23 & 0.156 \\
\hline $\begin{array}{l}\text { Employed } \\
\text { (yes) }\end{array}$ & 32 & 24 & $0.046^{*}$ \\
\hline $\begin{array}{l}\text { History of } \\
\text { Breast Cancer } \\
\text { (yes) }\end{array}$ & 61 & 2 & $0.002 * *$ \\
\hline $\begin{array}{l}\text { History of } \\
\text { Cancer in } \\
\text { Family (yes) }\end{array}$ & 54 & 5 & $<0.001 * * *$ \\
\hline $\begin{array}{l}\text { Frozen } \\
\text { foods(yes) }\end{array}$ & 71 & 8 & $0.003 *$ \\
\hline $\begin{array}{l}\text { Drinking } \\
\text { Herbal Tea } \\
\text { (yes) }\end{array}$ & 21 & 19 & $0.013^{*}$ \\
\hline $\begin{array}{l}\text { Tattoo or } \\
\text { colorful } \\
\text { cosmetics (yes) }\end{array}$ & 91 & 12 & $<0.001 * * *$ \\
\hline $\begin{array}{l}\text { Consume rice } \\
\text { daily (yes) }\end{array}$ & 95 & 29 & 0.131 \\
\hline $\begin{array}{l}\text { Canned, } \\
\text { prepared foods } \\
\text { (yes) }\end{array}$ & 89 & 11 & $0.048^{*}$ \\
\hline $\begin{array}{l}\text { Routine } \\
\text { exposure to } \\
\text { household } \\
\text { chemicals }\end{array}$ & 56 & 11 & $0.042 *$ \\
\hline $\begin{array}{l}\text { Water purifier } \\
\text { at home(yes) }\end{array}$ & 38 & 8 & 0.611 \\
\hline Plastic bottles & 30 & 18 & 0.806 \\
\hline $\begin{array}{l}\text { Fast Food } \\
\text { (Yes) }\end{array}$ & 83 & 19 & 0.804 \\
\hline $\begin{array}{l}\text { Indian Rice } \\
\text { (yes) }\end{array}$ & 75 & 10 & $0.012^{* *}$ \\
\hline $\begin{array}{l}\text { Cooked cereals } \\
\text { more than } 1 \\
\text { time in a week }\end{array}$ & 106 & 16 & 0.056 \\
\hline $\begin{array}{l}\text { Tuna, canned } \\
\text { in oil, drained }\end{array}$ & 93 & 10 & $<0.001^{* * *}$ \\
\hline $\begin{array}{l}\text { Mushrooms, } \\
\text { raw or cooked } \\
\text { (yes) }\end{array}$ & 36 & 28 & $<0.001^{* * *}$ \\
\hline
\end{tabular}

\begin{tabular}{|l|l|l|l|}
\hline $\begin{array}{l}\text { Green peppers } \\
\text { stuffed } \\
\text { with Foods } \\
\text { frequently } \\
\text { (yes) }\end{array}$ & 18 & 27 & $<0.001^{* * *}$ \\
\hline $\begin{array}{l}\text { Active } \\
\text { Smoking(yes) }\end{array}$ & 44 & 10 & $0.041^{* *}$ \\
\hline
\end{tabular}

Table 1: demographic factors, background diseases, and lifestyle in over 40 years old in Women Patients by Cancer disease

Urine Arsenic levels (U-As) in over 40 years old in Women Patients by Cancer disease. In a typical, multivariable-adjusted model (adjusted for all age group, smoking, daily regimen, Cosmetics and Tattoo, and menopausal status), urinary As Levels in all Breast Cancer patients and control groups who used to drink herbal teas (more than 3 times in a week) were significantly $(p=0.013)$ lower than others.

Tables 1 and 2 showed the mean of U-As levels in Breast Cancer patients and those in the control group in the range of over 40 years and 20 to 40 and of age, respectively. The mean concentration of total Arsenic in the urine of Stage III patients was significantly much higher than the control group $(0.054+0.009 \mathrm{mg} / \mathrm{L}$ vs. $0.011+0.008 \mathrm{mg} / \mathrm{L}, p=0.004)$. It might be described as an association between U-As and anthropometric factors, that is considered in specified analyses. Urine Arsenic levels in smokers: Although we found a significant difference between the mean U-As levels of recent active or passive smokers $(p=0.041)$.

Urine As levels in Menopausal Hormone Therapy: Long term use of menopausal hormone therapy for 3 months or longer (estrogen or estrogen plus progesterone; pills or patches caused increased U-As level $(p=0.003)$ in the total population of cases and control.

The results were selected confounders based on knowledge about risk factors for Breast Cancer and sources of Arsenic exposure. Results from multivariable models were stratified by age at enrollment $(20-29,30-39,40-49,50-59$ or $59-69$ years) and finalized studies as two groups of over 40 (Table 1) and 20 to 40 years old category (in Table 2). The pattern of all patient groups, the history of cancer in the family and especially Breast Cancer had significantly been observed while the statistics show patients in the age of younger group probably are at higher risk $(p=0.002)$ in comparison to the age of over 40 years $(p=0.001)$.

The association of Breast Cancer risk with total Arsenic levels did not differ between participants treated by surgery and/ or radiation $(p \geq 0.05)$ only $(\mathrm{OR}=1.41 ; 95 \% \mathrm{CI}: 1.2-1.4)$ and those treated with chemotherapy (OR=1.38; 95\% CI: 1.1-1.5), eliminating those factors. 
The Role of Diet in Urine Arsenic levels (U-As) in over 40 years old in Women Patients by Cancer disease

Consumption of food grown in arsenic-contaminated areas is another source of chronic arsenic exposure since agricultural products are cultivated using arsenic-contaminated groundwater. Many studies confirmed that contaminated groundwater used to grow vegetables and rice for human consumption probably lead to the significant pathway of arsenic ingestion. However, the type of arsenic species found in the foods was not investigated in this research, but we know that they are necessary to assess the risk among humans who ingest the diversity of foods. The consuming factors which impressively affected the results were: Frozen foods ( $p=$ $0.003)$; prepared and canned foods $(p=0.048)$; Indian Rice more than 3 times in a week $(p=0.012)$; Tuna, canned in oil or drained at least one in a week $(p=0.001)$ and some positive factors that showed the drinking herbal teas ( more than 3 times in a week lead to significant factor to reduce the risk factor of getting Breast cancers in the studied women over 40 year old ( $p=0.013$ ); Green peppers stuffed with Foods and also mushrooms in raw or cooked states, more than twice in the weekly diet $(p<0.001)$. Nevertheless, the results of the current study support the theory that food may be an important route of arsenic exposure in some regions and that these exposures may have long-term adverse health effects in humans but on the other hand, drinking endemic herbal teas and also consuming green pepper and mushrooms are a very essential role in preventing or treatment of breast cancer. Considering the widespread distribution of food, arsenic-contaminated food and the possible associated risks of disease should be regarded as a significant global issue.

\begin{tabular}{|l|l|l|l|}
\hline Characteristics & $\begin{array}{l}\text { Women } \\
(\mathrm{n}=101)\end{array}$ & $\begin{array}{l}\text { Control } \\
\text { group } \\
(\mathrm{n}=49)\end{array}$ & $\mathrm{p}$-Value \\
\hline $\begin{array}{l}\text { Age (mean } \pm \\
\text { SD) }\end{array}$ & $33.61+2.87$ & $\begin{array}{l}30.08+ \\
5.03\end{array}$ & 0.111 \\
\hline $\begin{array}{l}\text { As levels } \\
\text { (Mean } \pm \text { SE) }\end{array}$ & $0.042+0.003$ & $\begin{array}{l}0.011+ \\
0.025\end{array}$ & $0.004^{* *}$ \\
\hline $\begin{array}{l}\text { Body Mass } \\
\text { Index (BMI) } \\
\text { (mean } \pm \text { SD) }\end{array}$ & $25.654+0.428$ & $\begin{array}{l}24.289+ \\
0.672\end{array}$ & 0.102 \\
\hline $\begin{array}{l}\text { Academic } \\
\text { Education(yes) }\end{array}$ & 27 & 20 & 0.238 \\
\hline $\begin{array}{l}\text { Employed } \\
\text { (yes) }\end{array}$ & 74 & 31 & 0.065 \\
\hline $\begin{array}{l}\text { History of } \\
\text { Breast Cancer } \\
\text { (yes) }\end{array}$ & 81 & 13 & $<0.001^{* * *}$ \\
\hline $\begin{array}{l}\text { History of } \\
\text { Cancer in } \\
\text { Family (yes) }\end{array}$ & 61 & 21 & $0.032^{*}$ \\
\hline $\begin{array}{l}\text { Frozen } \\
\text { foods(yes) }\end{array}$ & 97 & 38 & 0.138 \\
\hline
\end{tabular}

Table 2: demographic factors, background diseases, and lifestyle in 20- 40 years old in Women Patients by Cancer disease

The correlation coefficient between average daily intakes of raw or cooked mushrooms, estimated using the food consumptionfood composition method and U Arsenic, was $0.12(p<0.001$, $\mathrm{n}=58)$, whereas that for green peppers was $0.15(p<0.001$, $\mathrm{n}=40$ ). That means consumption of mushrooms and green peppers can significantly reduce the $\mathrm{U}-\mathrm{As}$.

In current research, Cosmetics exposure are emphasized although in most investigations they were considered as low priority in consumer safety assessments since they are wrongly assumed to have no effect our health. Cosmetics are also considered an unlikely source of arsenic exposure and as a simple impurity, but are a leading cause of direct exposure among a many individual. Assessing the amount 
of dermal absorption from a single component in a cosmetic product is complex and depends on many factors such as the concentration of arsenic in the product, the amount of product applied, the length of time left on the skin and the presence of emollients and penetration enhancers in the cosmetic product .The results of consuming colorful cosmetics and Tattoo shown the significant results $(p=0.011)$ in 20 - 40 years old in Women Patients by Cancer disease.

\section{Conclusion}

Cancer with arsenic compounds has been reported in many parts of the world associated with our BGR. The disease affects all organs of the body, and every year many victims of cancer suffer from severe symptoms and even death. Arsenic compounds are present in the human body and environment in an inorganic and organic form. Inorganic arsenic includes arsenite and arsenic, can also be presented in the environment in the form of methyl (monthly arsenic acid and dimethyl arsenic acid). Arsenic, especially inorganic arsenic, is well absorbed through the gastrointestinal tract rivers $(80 \%$ $-90 \%$ ) and will be scattered throughout the body. It is often metabolized by methylation and excreted mainly in the urine. Methylation of inorganic arsenic compounds is said to undergo a detoxification process.

Contamination of various sources with arsenic compounds, especially inorganic arsenic, has caused great concern for human health. Prolonged exposure to arsenic can cause cancers of the skin and internal organs, including the liver, breast, and bladder, as well as increase mortality. The non-cancerous effects of oral arsenic on the gastrointestinal tract are cardiovascular, pulmonary, immunological, neurological, endocrine (such as diabetes) and skin. The tests used to diagnose poisoning are based on the blood concentration of arsenic, its concentration in urine, hair and nails.

Measuring the urinary concentration of arsenic is the most valid test for people who have been exposed to it. Arsenic poisoning is life-threatening and requires supportive measures (administration of crystalloid fluids, positive inotropic drugs, and treatment of cardiac dysrhythmias), decontamination (washing of the gastrointestinal tract-rivers, and the use of activated charcoal in some patients).

Determining arsenic-contaminated areas or contaminated materials, including food or soil, as well as raising awareness of the consequences of arsenic poisoning with arsenic in humans and increasing public awareness, are important issues to consider.

In the present study, Urinary Arsenic concentration in Breast Cancer patients over 40 years old was 5 times, and in patients, 20-40 years old group was 4 times more than control groups. The results revealed that $\mathrm{U}$ Arsenic contents in Breast cancer patients in all ages category are much lower by eating Green peppers stuffed with Foods frequently $(p<0.001)$. The u-As level was significantly higher in direct correlation between anthropometric factors (BMI levels; $p<0.041$, dietary habits such as eating frozen and canned foods, Tuna, raw mushrooms, use of colorful cosmetics and Tattoo and lifestyle was found in all patients of cases and control. Drinking Herbal Tea caused significantly decreased u Arsenic concentration in both older and younger age subgroups and in the younger groups of women this is more remarkable. Consuming Indian rice, history of cancer in the family, smoking, routine exposure to household chemicals significantly causes increasing the risk of breast cancer associate with specific BGR.

\section{Acknowledgements}

Especially, we are very thankful to the medical team and staff of Shiraz Educational Hospitals for technical support of this study and also to the Nutrition and Food Sciences Research Center, Tehran Medical Sciences, Islamic Azad University, Tehran, Iran

\section{Conflict of Interests}

It is declared that the authors neither have any financial gain nor conflict of interests regarding this paper.

\section{References}

1. Karimi G., Ziarati P (2015) Heavy Metal Contamination of Popular Nail Polishes in Iran, Iranian Journal of Toxicology 9(29): 1290-1295; http://ijt.arakmu.ac.ir/ article-1-410-en.pdf;

2. ZIARATI P., HOCHWIMMER B., LAMBERT BROWN D., MORADI M., CRUZ-RODRIGUEZ L (2020) Breast Cancer disease and Heavy Metal: Cadmium as Key in Medical Geology. Journal of Gynecology and Women's Health Care 2020 2(2): 1-13.

3. Ziarati P., Mirmohammad Makki F.S., Vambol S., Vambol V (2019) Determination of Toxic Metals Content in Iranian and Italian Flavoured Olive Oil. Acta Technologica Agriculturae Journal 22(2): 64-69. DOI: 10.2478/ata2019-0012.

4. Tamjidi, S., Esmaeili, H., \& Moghadas, B. K. (2019) Application of magnetic adsorbents for removal of heavy metals from wastewater: a review study. Materials Research Express 6(10): 102004.

5. Chakraborti D, Rahman MM, Paul K, Chowdhury UK, Sengupta MK, Lodh D, et al. (2002) Arsenic calamity in the Indian subcontinent What lessons have been learned? Talanta 58(1): 3-22.

6. Peshut PJ, Morrison RJ, Brooks BA (2008) Arsenic Speciation in marine and shellfish Samoa. Chemosphere 71(3): 484-492.

7. Emsly J (2003) Nature,s building block: An A-Z guide to the elements. 1st ed. oxford: Oxford University Press 43: 513-529.

8. Singh AP, GeolR.K,Kaur T (2011) Mechanism pertaining to arsenic toxicity.Toxicol Int 18(2): 87-93.

9. Roy P, Saha A (2002) Metabolism and toxicity of arsenic: a human carcinogen. Curr Sci 82(1): 38-45. 
10. Obinaju BE (2009) Mechanisms of arsenic toxicity and carcinogenesis. Afr J Biochem Res 3(5): 232-237.

11. Health Canada [Internet](2006) Guidelines for Canadian Drinking Water Quality; Guideline Technical DocumentArsenic [Cited, May, 2006]. Available from: http://www. hcsc.gc.ca/ewh-semt/alt_formats/hecssesc/pdf/pubs/ water-eau/arsenic/arsenic-eng.pdf

12. US Government Code of Federal Regulations [Internet] (2015)Labeling regulation. Title 21: Part 74, Section 2025 [Published, Jan 4, 2008; Cited, Feb 5, 2015]. Available from: http://www.fda.gov/cosmetics/cosmeticlabelingl abelclaims;

13. Ziarati, P., Farasati Far, B., Mashayekhi, E., Sawicka, B. (2019) Removing arsenic by food-processing waste (Zizyphus jujuba seeds) and study on its adsorptive properties. Technogenic and ecological safety, 5(1): 6270. doi: 10.5281/zenodo.2604648.

14. Ziarati P., Shirkhan F., Mostafidi M., Tamaskani-Zahedi M (2018) An Overview of the Heavy Metal Contamination in Milk and Dairy Products. Acta Scientific Pharmaceutical Sciences 2.7 (2018): 08-21.

15. Ziarati P., Mirmohammad Makki F.S., Vambol S., Vambol V. Determination of Toxic Metals Content in Iranian and Italian Flavoured Olive Oil. Acta Technologica Agriculturae Journal. 2019; 22(2): 64-69. DOI: 10.2478/ ata-2019-0012.

16. Datta DV, Mitra SK, Chhuttani PN, Chakravarti RN (1979) Chronic oral arsenic intoxication as a possible aetiological factor in idiopathic portal hypertension (noncirrhotic portal fibrosis) in India. Gut 20(5): 378-84.

17. Ziarati P., Vambol V., Vambol S. Use of inductively coupled plasma optical emission spectrometry detection in determination of arsenic bioaccumulation in Trifolium pratense L. from contaminated soil. Ecological Questions ,2020; 3(11 ): 1-11. Available from http://dx.doi. org/10.12775/EQ.2020.003

18. Tseng CH (2008) Cardiovascular disease in arsenicexposed subjects living in the arseniasis-hyperendemic areas in Taiwan. Atherosclerosis 199(1): 12-18.

19. Mukherjee A, Sengupta MK, Hossain MA, Ahamed S, Das B, Nayak B, et al. (2006) Arsenic contamination in groundwater: a global perspective with emphasis on the Asian scenario. J Health Popul Nutr 24(2): 142-163.

20. Rahman MM, Chowdhury UK, Mukherjee SC, Mondal BK, Paul K, Lodh D, et al. (2001) Chronic arsenic toxicity in Bangladesh and West Bengal, India--a review and commentary. J Toxicol Clin Toxicol 39(7): 683-700

21. Haghayegh, M., Zabihi, F., Eikani, M. H., Kamya Moghadas, B., \& Vaziri Yazdi, S. A. (2015) Supercritical fluid extraction of flavonoids and terpenoids from herbal compounds: Experiments and mathematical modeling. Journal of Essential Oil-Bearing plants 18(5): 1253-1265.

22. Moghadas, B. K., Safekordi, A. A., Honarvar, B., Kaljahi, J. F., \& Yazdi, S. V. (2012) Supercritical Extraction of Flavonoid Compounds from Dorema aucheri Boiss. Experimental and Modeling Using $\mathrm{CH} 2 \mathrm{Cl} 2$ as CoSolvent. Asian Journal of Chemistry 24(8).

23. Petrusevski B, Sharma SK, Schippers JC, Shordt K (2007) Arsenic in drinking water. Delft: IRC International water and Sanitation Center 2007: 1-11.

24. M Mosaferi, H Taghipour, AM Hassani, M Borghei, Z Kamali, A Ghadirzadeh (2008) Study of Arsenic Presence in Drinking Water Sources: A Case Study. Iran J Health Environ 1: 18-27.

25. López-Carrillo, L., Hernández-Ramírez, R. U., Gandolfi, A. J., Ornelas-Aguirre, J. M., Torres-Sánchez, L., \& Cebrian, M. E. (2014) Arsenic methylation capacity is associated with breast cancer in northern Mexico. Toxicology and applied pharmacology 280(1): 53-59.

26. Lin, L. M., Li, B. X., Xiao, J. B., Lin, D. H., \& Yang, B. F. (2005) Synergistic effect of all-trans-retinoic acid and arsenic trioxide on growth inhibition and apoptosis in human hepatoma, breast cancer, and lung cancer cells in vitro. World journal of gastroenterology: WJG 11(36): 5633.

27. Khanjani, N., Jafarnejad, A. B., \& Tavakkoli, L. (2017) Arsenic and breast cancer: a systematic review of epidemiologic studies. Reviews on environmental health 32(3): 267-277.

28. López-Carrillo, L., Gamboa-Loira, B., Gandolfi, A. J., \& Cebrián, M. E. (2020) Inorganic arsenic methylation capacity and breast cancer by immunohistochemical subtypes in northern Mexican women. Environmental Research 109361.

29. Cioloboc, D., \& Kurtz, D. M. (2020) Targeted cancer cell delivery of arsenate as a reductively activated prodrug. JBIC Journal of Biological Inorganic Chemistry 1-9.

30. Palma-Lara, I., Martínez-Castillo, M., Quintana-Pérez, J. C., Arellano-Mendoza, M. G., Tamay-Cach, F., ValenzuelaLimón, O. L., ... \& Hernández-Zavala, A. (2020) Arsenic exposure: A public health problem leading to several cancers. Regulatory Toxicology and Pharmacology 110: 104539.

31. Yoshida T, Yamauchi H, Fan Sun G (2004) Chronic health effects in people exposed to arsenic via the drinking water: dose-response relationships in review. Toxicol Appl Pharmacol 198(3): 243-252.

Copyright: C2020 CRUZ-RODRIGUEZ Luis. This is an open-access article distributed under the terms of the Creative Commons Attribution License, which permits unrestricted use, distribution, and reproduction in any medium, provided the original author and source are credited. 